\title{
Why diabetes support?
}

\begin{abstract}
Why do patients with diabetes need ongoing support? Why do we need to do more than prescribe medication and exam patients for complications? By supporting and coaching patients, hopefully, the patient will achieve patient-centred management and control.
\end{abstract}

Volume 4 Issue 2 - 2017

\author{
Nicolette Whiley \\ University of South Wales, South Africa
}

Correspondence: Nicolette Whiley, University of South Wales, P.O. Box 2334 Lone hill 2062, South Africa, Tel +27 82224 7268, Email nicci@diabetessupport.co.za

Received: June 29, 2016 | Published: March 16, 2017

\section{Short communication}

I have spent the last 15 years working in one or other way with diabetes. I have nursed patients with diabetes, taught patients with diabetes, sold diabetes drugs, trained sales representative about diabetes drugs, attended congresses on the latest treatment options and guidelines for patients with diabetes. I even have family members with type 1 and type 2 diabetes as well as pre-diabetes. Yet I have never closely considered the person at the very heart of diabetes - the patient.

Health Care Providers (HCPs) - including myself - have generally been quick to label, in particular, the patient with type 2 diabetes, as 'overweight, lazy and non-compliant'. But something dawned on me one day whilst training sales representatives on the disease. How motivated would I be if I was told I had a chronic and, as yet incurable disease? How motivated would I be if I was told that if I lived long enough I would have to inject myself with insulin, that all that can be done is to delay the inevitable with drugs and hope that I don't die sooner from diabetes-related complications? That even if I adhered to the lifestyle changes and treatment, eventually, my pancreas would fail and insulin would be the norm for me? I would need a lot of encouragement to stay motivated in this 'one step forward, two steps back' disease. This is what inspired me to move away from the corporate environment to see how best I could support the person with type 2 diabetes. What role can I play in improving the lives of patients newly diagnosed and/or in the early stages of this progressive disease? How can I assist this patient to possibly delay the time to insulin and reduce the risk of complications?

Typically, the HCP has very little time to explain the gravity of this chronic, life-threatening disease and the patient returns home with a diagnosis, instructions to lose weight and exercise, eat differently and take, on occasion, a handful of tablets. He does not necessarily feel ill, however, he has been told that if he does not adhere, he will go blind, have his foot amputated or die of a heart attack. A few months later he returns for an $\mathrm{HbA} 1 \mathrm{c}$ test and predictably, the results are now worse. The patient gets labelled as having failed on treatment, and is "punished" with the initiation of insulin therapy. Only then, is the severity of the disease starting to sink in.

But what if we changed our approach? Let's wind back the clock. If we paid closer attention to this patient from the beginning, helped him to understand right from the outset just how serious this disease is, and most importantly, support and encourage this patient on a continual and non-punitive basis, we could perhaps extend the time to the inevitable. Instead of labelling the patient as a failure on oral therapy, let us not forget that it is the disease that has also failed the patient. The patient with diabetes is central to his/her own diabetes management. These are, after all, the individuals who undertake the day-to-day management of the disease. They do, however, need continual support and encouragement from a team they trust and have confidence in, in order to successfully succeed. The majority of people living with diabetes cannot go through this journey on their own. We need to be a supportive partner, not sit in judgment of them from the sidelines.

\section{Acknowledgments}

None.

\section{Conflicts of interest}

The author declares there is no conflict of interest. 